\title{
Música Indígena no Mercado: Sobre Demandas, Mensagens e Ruídos no (Des)Encontro Intermusical'
}

Luís Fernando Tem-se verificado ultimamente um constante aumento na procura, por parte dos Hering Coelho povos indígenas que vivem no Brasil, de uma inserção no mercado da música, aqui entendido de uma forma geral como o espaço onde se vendem e compram produtos como CDs e shows. Este movimento está inserido num outro mais amplo, e que não é de hoje e nem acontece só no Brasil, de apropriação, por estes povos, das técnicas de registro, tanto de fonografia quanto de fotografia e vídeo $^{2}$. Entre os índios guarani, por exemplo, este movimento tem se mostrado cada vez mais significativo, como o mostra a recorrência de gravações e comercialização de CDs de "cantos tradicionais". Dois exemplos dessas produções são Nande Rekó Arandu - "Memória Viva Guarani" (Fonseca de Oliveira 1998), gravado na aldeia Jaexaá Porã, em Ubatuba, litoral de São Paulo, em 1998, com músicos das aldeias Rio Silveira (São Sebastião-SP), Sapucai (Angra dos ReisRJ), Morro da Saudade (Parelheiros-SP) e Jaexaá Porã (Ubatuba-SP) ${ }^{3}$ e Mboraí Marae'ÿ - "Cantos Sagrados" (Tombini 2000) gravado por músicos das aldeias de Morro dos Cavalos e Massiambú, litoral de Santa Catarina, em 2000. Discos como estes, direcionados para o público em geral, comumente resultam de cooperações - que se dão de diversas formas - entre índios em demanda do referido mercado e pessoas da sociedade nacional que muitas vezes não são antropólogos ou etnomusicólogos ${ }^{4}$, mas sim produtores musicais ou profissionais de outras áreas, interessados em tal tipo de trabalho e demandantes, de algum modo, das "culturas indígenas". Além de gravar CDs, grupos musicais indígenas têm se apresentado em vários tipos de espaços e eventos, como universidades, 
Os índios guarani pertencem à família lingüística Tupi-Guarani e vivem numa região que se espalha pelo Paraguai, Argentina, Uruguai, Brasil e Bolívia. No Brasil, ocupam um espaço que inclui os estados de Mato Grosso do Sul, Paraná, São Paulo, Rio de Janeiro, Espírito Santo, Santa Catarina e Rio Grande do Sul, tendo sua população no país estimada em 35.000 pessoas $^{6}$. Não raramente, vivem próximos às cidades, tendo familiaridade com elementos da cultura ocidental como rádio e televisão, o que é freqüentemente tomado pelo senso comum como índice de "aculturação", no sentido de "perda" de uma cultura que seria "autêntica", ou "original". A proximidade dos guarani com a música ocidental é tão antiga quanto o contato com os invasores europeus, especialmente missionários, que vem desde o século $\mathrm{XVI}^{7}$. Uma característica marcante de seu sistema musical atual é o uso de instrumentos de cordas como o violão (mbaraka) e a rabeca (rave, ou guyrapa-pe), de utilização largamente difundida ${ }^{8}$, ao lado do ãgua-pu (tambor), takua-pu (bastão de ritmo) e mbaraka-mirin (chocalho).

A reflexão que aqui busco apresentar surgiu fundamentalmente do contato que tive com índios guarani moradores da aldeia Mbiguaçu, situada no município de Biguaçu, no litoral de Santa Catarina, a aproximadamente 25 quilômetros de Florianópolis ${ }^{9}$. Realizei ali uma pequena pesquisa, efetivada na forma de visitas (com duração média de um dia) à aldeia entre outubro de 1998 e setembro de 1999, que resultou numa breve etnografia sobre as práticas musicais na aldeia (Coelho 1999). Na época, acompanhei ali a constituição de um "coral", chamado Yvytchí Ovy ("Nuvens Azuis"), formado por crianças e adolescentes a partir da iniciativa e sob a coordenação de jovens índios, cujo objetivo era montar um repertório de música guarani com vistas a apresentações dentro e fora da aldeia. Após concluída a pesquisa - que se concentrou justamente no repertório do coral - continuei em contato com os seus integrantes, sendo que terminei por atuar como uma espécie de "assistente" do coral durante boa parte do ano 2000, assumindo funções como a obtenção de uniformes $^{10}$, o estabelecimento de contatos para apresentações e a também busca de apoio para a gravação de um CD, da forma como desejavam os músicos. Assim, acompanhei o coral em apresentações em lugares como igrejas, escolas, centros comunitários e universidades. O mote dessas apresentações era, via de regra, de caráter assistencialista, sendo que o pagamento que o coral obtinha era sobretudo na forma de doações de alimentos. Por decisão pessoal, abandonei o "cargo" de assistente do coral Yvytchí Ovy aproximadamente em fins de 2000. Durante o mestrado em antropologia, fui pesquisar outras músicas, de outros índios (Coelho 2003), tendo se tornado muito mais raras minhas visitas aos guarani. Até onde sei, contudo, o coral Yvytchí Ovy continua em plena atividade e parece ter encontrado recentemente entre os juruá ${ }^{11}$ parcerias que apontam para vias concretas da realização da gravação do $C^{12}$. De uma maneira geral, este convívio com as atividades 
e as demandas do coral me colocou por algum tempo entre, de um lado, um grupo de músicos indígenas demandantes da inserção num mercado musical e, de outro, representantes deste próprio mercado, sejam eles pessoas do público em geral e sejam, principalmente, funcionários de órgãos oficiais de "cultura" ou produtores musicais. Foi principalmente no contato com alguns representantes destes dois últimos grupos que verifiquei o quanto é forte uma determinada idéia pré-concebida sobre o que vem a ser o "índio" e o quanto ela eventualmente influi no interesse que o mercado e a mídia possam ter na música indígena. De fato, no período em que acompanhei de perto as atividades do coral, vi fracassarem muitas tentativas de obter apoio para a gravação do CD em virtude, creio, justamente de um descompasso existente entre as demandas das partes envolvidas, e é para elementos deste descompasso que tento apontar aqui. O universo de observação é estendido e complementado, além deste contato com o coral Yvytchí Ovy, pelo exame de CDs já presentes no mercado (conforme adiante).

Entendendo, então, a demanda dos guarani - e dos povos indígenas de forma geral - em direção ao mercado da música como algo que acontece num terreno deveras turbulento que é o do encontro entre índios e sociedade nacional no Brasil, pretendo, neste breve exercício, levantar algumas questões, que giram em torno da delimitação de alguns elementos presentes, por um lado, nos interesses que movem os índios em tal demanda e, por outro, nos interesses e na forma de recepção que o mercado possa ter com relação às músicas indígenas. Mais do que buscar fatores que poderiam ser tomados como determinantes do sucesso ou do fracasso comercial de discos de música indígena, busco apontar para algumas falas, por assim dizer, do diálogo que, às vezes precariamente, às vezes com algum êxito, constantemente ensaia desenrolar-se no cenário aqui esboçado.

No discurso de músicos indígenas sobre a importância que teriam para eles atividades como apresentações públicas e a produção de gravações comerciais, duas afirmações recorrem: por um lado, considera-se importante resgatar elementos da própria cultura, mostrando aos brancos que ela se mantém "preservada"; por outro, a busca da obtenção de melhorias materiais para as comunidades também é mencionada, seja através de doações recebidas em troca das apresentações, seja através do dinheiro esperado com a venda de CDs. Ouvi em Mbiguaçu depoimentos neste sentido que são perfeitamente coerentes com o discurso de Timóteo Verá Popyguá em depoimento que faz parte do encarte do CD Nande Reko Arandu (Fonseca de Oliveira, op.cit.), onde focaliza questões como preservação ecológica, conciliação entre os diferentes povos e respeito à diversidade cultural. Ali se opera, de acordo com Montardo (1999:204), uma "estratégia política de apropriação do conceito de cultura"13. 
Junto deste discurso de preservação cultural - e entrando de fato como um elemento de sua própria constituição -, um espírito criativo, de abertura e curiosidade, marca a prática musical guarani. Não raro ouvi em Mbiguaçu manifestações de interesse em aprender a tocar instrumentos "do juruá", como saxofone e guitarra elétrica, ou então o empenho em pegar a "batida" do pagode ao violão. Tal abertura é notada por Schaden já na década de 50, sendo avaliada por ele como um fator dissociativo:

Talvez o gôsto, a quase fascinação pela música exótica e pelas melodias estranhas devam ser apontados mais uma vez na história guaraní como fôrças ativas na substituição de ideais de cultura, tal como se deu com o cantochão dos jesuítas de há quase três séculos (Schaden 1962:155).

Neste mesmo livro, o autor apresenta algumas estrofes de "cantos mais ou menos profanos", segundo ele aprendidos de um grupo mbÿá14 vindo do Paraguai pelos ñandéva moradores da aldeia do Itariri, no litoral paulista, e conhecidas "assim como se conheciam as mais recentes modinhas de carnaval" (idem:159). A comparação das letras destes cantos com estrofes dos que atualmente fazem parte do repertório do coral Yvytchí Ovy revela uma grande semelhança:

1. Oré oroópotá pará ovái; oró ú ãuã takuarý-porã. (Queremos ir para o outro lado do mar, para chupar cana). (Schaden 1962:159)

2. H'oro'ó potá, ÿguatchú rovai; takuarÿ porã oroÿ'ú avã. (Pretendemos ir do outro lado do oceano para tomar a água sagrada que está na taquara). (Coelho 1999: 44)

3. Éguedjý, tupã raý; djadjapó piêta porã, djadjapó piêta, overá. (Desce, filho de Deus - do trovão -, vamos fazer uma festa bonita, vamos fazer uma festa, está relampejando). (Schaden 1962: 160)

4. Eguedjÿ tupã raÿ, eguedjÿ tupã radjÿ; dja'djapó pieta porã, djadjapó pieta werá (Desce, filho de Deus, desce filha de Deus; vamos fazer a festa bonita, vamos fazer a festa sagrada). (Coelho 1999: 44)

As estrofes 1 e 3, com suas traduções, são as registradas por Schaden a partir de pesquisas feitas no estado de São Paulo entre 1946 e 1954, enquanto que as 2 e 4 foram recolhidas por mim em Mbiguaçu em 1999 (com grafia e a tradução tal como foram dadas pelos próprios informantes). A comparação (1 com 2 e 3 com 4) aponta para raízes profundas da constituição do repertório atual de canções guarani - aquele que hoje se direciona a shows e CDs -, bem como para uma estabilidade espaço-temporal deste repertório - pelo menos ao nível das letras (Coelho 2000) ${ }^{15}$ - que abrange um período de 50 anos e um território que se espalha pelos estados de São Paulo, Santa Catarina e Paraná, numa rede de comunicação que alcança o Paraguai e 
não deixa de estar atenta às "mais recentes modinhas de carnaval" (Schaden op.cit.). O estudo de Setti (1994/ 95) também aponta para uma grande estabilidade no sistema musical guarani.

Num horizonte mais geral, a etnologia indígena das terras baixas da América do Sul tem recorrentemente demonstrado que o intenso contato intersocietário não constitui novidade alguma para os povos indígenas e que a circulação de influências que ele traz consigo não se dá num só sentido. Vários trabalhos têm chamado a atenção para os modos criativos empregados por estes povos na busca de articulações políticas com estrangeiros e sobre como as situações de contato intercultural fornecem elementos que entram na constante reelaboração das diferentes visões de mundo. O contato, quando não é caracterizado pelo etnocídio, vem sido entendido como algo constituinte ${ }^{16}$. Bruce Albert, para citar um exemplo, vê, a partir de suas pesquisas entre os yanomami, a formação das etnicidades amazônicas contemporâneas, em sua apropriação política de elementos do discurso do "homem branco", não como um conjunto de teatralidades alienadas, mas sim como

um processo de adaptação criativa cujo trabalho simbólico e político propõe condições da possibilidade mesma de um espaço de interlocução e de negociação interétnica, portanto de uma reversibilidade do discurso de dominação colonial (Albert 1993:351, tradução minha).

A formação dos corais guarani, seus discursos, apresentações e CDs são fenômenos claramente relacionados à busca por este espaço de interlocução e negociação interétnica. Estes repertórios musicais são constituídos a um tempo tradicionalmente e na relação com o outro. Os aspectos estético e político são ali inseparáveis.

Os exemplos etnográficos de sistemas estético-musicais onde a "tradição" não exclui a abertura e a flexibilidade em vários níveis se multiplicam: Piedade (1997:149-152) explora a hipótese de uma origem arawak dos cantos kapiwayá dos ye'pâ-masa (tukano) da região do alto Rio Negro, sugerindo que parte do repertório "tradicional" ye'pâ-masa não teria sido criado por eles de forma "livre de influências externas", mas justamente no contato com grupos arawak. Seeger (1987) mostra o profundo interesse dos suyá pela performance de músicas estrangeiras, que tanto podem ser as de Yamuricumã, aprendidas de seus vizinhos índígenas no AltoXingu, quanto canções folclóricas norte-americanas aprendidas com o antropólogo. Van Velthem (1995) explora as relações entre a ordem socio-cosmológica e a estética wayana (caribe) apontando para a importância simbólica da caça e sua relação com a guerra, mostrando que é "no quadro das representações ligadas à guerra indígena que podemos encontrar os fundamentos da representação dos objetos industriais na sociedade Wayana." (:264): os bens industriais incorporados à sociedade são pensados como os cativos de guerra que, 
trazidos à aldeia, são passíveis de uma socialização, de uma "domestificação" e incorporação. Andando um pouco mais sobre o mapa, ouvimos pedaços de guarda-chuvas e de bicicletas soando como componentes de instrumentos musicais (no caso, especificamente a sanza) dos gbáyá da África Central (Dehoux 1992), sendo que Arom (1991:149) mostra que nem isto nem a confecção de tambores rituais com coisas como silenciadores de caminhão, prejudicam a princípio os aspectos culturalmente relevantes - do ponto de vista êmico - dos sistemas musicais destes povos.

Mas se a academia, ou parte dela, parece estar superando aquela concepção que não pode entender a fluidez e a mudança das culturas indígenas senão como mera fragilidade sua, indo na direção do reconhecimento da agência indígena e do entendimento do contato intersocietário não como algo acidental, mas como elemento constituinte mesmo da socialidade humana, a sociedade brasileira, que aqui se mostra através de coisas como o mercado de CDs, órgãos oficiais de "cultura" e mesmo programas de televisão" , parece negar o índio cuja figura não corresponda a uma certa invenção romântica. Fatos como o gosto dos guarani por músicas exóticas como a sertaneja, a MPB ou qualquer outra que lhes chegue aos ouvidos, e mesmo a utilização de instrumentos como o violão (mbaraka) e a rabeca (rave), muitas vezes são tomados como índices daquilo que seria uma lamentável "perda de cultura" que (num efeito curioso) afastaria o índio do seu "estado natural", tornando-o "menos autêntico". Os guarani têm consciência disto, e "vestem-se de índio" para seus shows... "Mas essa roupa é igual à que eles usavam há 500 anos?", perguntou-me certa vez um produtor preocupado com a autenticidade do "produto". Creio que este tipo de questão aponta para uma idéia específica de "Natureza", sendo que o estereótipo do "índio" é eleito como seu principal representante. Sobre esta idéia ocidental de Natureza, Lenoble (1990) mostra que no pensamento grego as ordens social e natural eram uma única coisa, coisa que foi dissociada no mundo judaico-cristão com a separação do homem ocidental - e de seu Deus - do mundo da Natureza. Indo nesta mesma direção, Marilena Chauí mostra que

A phýsis - traduzida para o latim como natura e para o português como natureza - é a fonte originária de todas as coisas, a força que as faz nascer, brotar, desenvolver-se, renovar-se incessantemente; é a realidade primeira e última, subjacente a todas as coisas de nossa experiência (Chauí 2002:46-47).

O deslocamento que se observa entre a noção grega de phýsis e a idéia de natureza do senso comum ocidental contemporâneo ajuda a desnaturalizar esta última, mostrando ser ela "menos uma realidade passiva apercebida que uma atitude do homem perante as coisas" (Lenoble 1990:200). Uma atitude, uma idéia que, em sua forma atual - de paraíso intocado - entra como ingrediente principal na construção do estereótipo indígena. 
A metáfora da relação entre o mármore e a murta, conforme desenvolvida por Viveiros de Castro (1992), é especialmente inspiradora para se pensar este encontro entre uma sociedade que - pelo menos num de seus aspectos mais evidentes e, talvez, mais gerais - tende a buscar na permanência e na imutabilidade alguns de seus valores centrais (que, projetados sobre o "selvagem", seriam uma espécie de condenação) e outra, onde o dinamismo parece constituir a base fundamental de sua perpetuação. Interessantemente, a "cultura do mármore" ocidental não parece ver para si mesma a aculturação como um perigo: não se sente dissolver por comer comida chinesa ou ouvir música guarani.

Lévi-Strauss (1993) mostra que a noção da irredutibilidade mútua entre os elementos da díade, que no presente caso é constituída pelos músicos indígenas de um lado e o mercado de outro, estaria presente no próprio entendimento ameríndio sobre a questão, ao passo que no Ocidente ela - a díade - tenderia a ser pensada sob o signo da identidade. Menezes Bastos retoma estes desenvolvimentos e mostra que o encontro colonial

constitui uma 'relação de contradição', mesmo que o colonizador nele se faça presente - (...) - através de um personagem cuja modalidade de representação sobre o selvagem se caracterize como idílica, filantrópica e humanitarista. Mesmo que esta modalidade de representação, superando a demarcação por assim dizer meramente assistencialista, intente saltar ao nível de uma ideologia/utopia na direção da aliança política interétnica, (...) (Menezes Bastos 1996:168-169).

Viveiros de Castro (2000), apontando também nesta direção, demonstra, ao analisar narrativas de diferentes povos indígenas, como o contato com os brancos é entendido pelo pensamento ameríndio como um encontro não entre irmãos, mas entre primos cruzados - essencialmente desiguais e mutuamente necessários.

A demanda indígena em direção ao mercado aqui em questão mostra, então, ter como um de seus aspectos a busca criativa de articulações políticas com o homem branco, isto dentro de uma concepção deste encontro que entenderia a desigualdade complementar e a irredutibilidade como características do sistema. Um senso estético aberto e flexível, que digere e assimila com desenvoltura elementos exógenos, ressignificandoos tanto na permanente construção da "tradição" quanto na elaboração de mensagens específicas para interlocutores com quem se tenha o que negociar, é aqui característica marcante. A sociedade nacional, aqui centralmente representada pelo mercado fonográfico interessado na música indígena tem, por outro lado, muita dificuldade para reconhecer o diferente onde não possa encontrar aquilo que inventou como o "índio", invenção que aponta antes para seu inventor - e sua idéia de natureza - do que para algum outro realmente existente. Uma das faces da busca por este índio inventado seria a de uma surdez com relação ao seu discurso real, e isto eventualmente sob a superfície de ideais como o da "aliança intercultural". 
É certo, como já apontei no início, que a presença de produtos relacionados à música indígena é cada vez mais forte no mercado (apesar de ainda ser relativamente muito pequena), o que indica que há abertura para (algum) consumo desta música e que os ruídos, as dificuldades de comunicação para as quais tento apontar aqui, apesar de bem reais, não atuam de forma soberana, mas entram como ingredientes - entre outros - de uma constante e complexa negociação. Mensagens musicais belíssimas como as dos guarani, se têm muitas vezes encontrado ouvidos abertos em diversos lugares - coisa que não se pode negar - têm tantas outras batido contra paredes acusticamente isoladas. E, lembre-se de passagem, se eles têm conseguido eventualmente abrir algumas brechas em sua busca de articulações políticas, algo absolutamente fundamental - o território - Ihes continua sendo sistematicamente negado.

Finalizo com algumas considerações a partir da audição de dois CDs de "música indígena" disponíveis no mercado - Nande Reko Arandu (Fonseca de Oliveira op.cit) e o álbum duplo Mehinaku - Message from Amazon (Pinagé 2001) - que podem empiricamente apontar para algumas das questões que tenho tentado levantar aqui. No primeiro, chama a atenção o uso do ravé (rabeca) e do mbaraka (violão), junto ao mbarakamirin (chocalho), ãgua-pu (tambor) e takua-pu (bastão de ritmo) nas performances dos músicos guarani, sendo que as melodias se constróem dentro de um ambiente harmônico invariável, determinado pelo acorde que resulta da afinação específica usada no $m$ baraka $^{18}$. Esta música evidencia um diálogo de séculos com a "música ocidental" que é constituinte da música tradicional guarani, tal como é reconhecida por seus próprios praticantes. Nota-se ali a livre apropriação e reelaboração, dentro do sistema musical guarani, de elementos exógenos, sem que isto implique - como deixa claro o discurso nativo - na dissolução das fronteiras entre a música guarani e a do juruá. Aprofundamentos analíticos futuros poderão pôr num plano de comparação em termos mesmo dos usos de relações intervalares, escalas, motivos, tonalidades, timbres, formas, ritmo os repertórios "sagrado" e "profano" guarani, que Dallanhol (2002) aproxima respectivamente aos conceitos nativos de jerojy e jeroky. No caso das escalas musicais, por exemplo, sugiro - a partir de dados da aldeia Mbiguaçu (Coelho 1999) - que nas melodias do repertório "profano" guarani se parece usar uma espécie de "seleção" de alturas da escala de tipo diatônica maior ocidental, com o uso privilegiado de seus graus I, II, III, $V$ e, com menor freqüência, IV (conforme transcrições das canções de criança em Coelho 1999) dentro do âmbito de uma oitava, com freqüente estabilização da tônica no grau I por meio de movimentos como o de quarta ascendente do grau $\mathrm{V}$ para o $\mathrm{I}$, modo principal de consolidação do centro tonal ${ }^{19}$ na música ocidental desde o período barroco. Já os cantos sagrados têm sua especificidade caracterizada pelo uso de recitativos e melodias que fazem variar terças maiores e menores em torno de um centro tonal, conforme demonstra Montardo (2002) no mais aprofundado estudo sobre a música ritual guarani disponível atualmente. 
O disco Mehináku: Message from Amazon faz parte de um projeto que inclui, além da gravação fonográfica, a produção de fita de vídeo e livro focalizando aspectos da cultura dos índios mehináku, que são falantes de uma língua da família aruák e vivem dentro dos limites do Parque Indígena do Xingu, no estado de Mato Grosso. A população dos mehináku em 1999 era de 183 pessoas (Ricardo 2000:12) ${ }^{20}$. A produção é muito bem feita, com excelente qualidade gráfica e qualidade técnica das gravações, tendo tudo para obter sucesso comercial, até como produto de exportação; ali o que se oferece ao público é justamente um índio ainda intocado, imerso em seu paraíso. O álbum fonográfico duplo traz um encarte com 58 páginas contendo mapas, fotos, reproduções de desenhos feitos pelos índios e textos - em português e inglês - com algumas informações breves sobre os repertórios, os mitos e rituais a eles relacionados, bem como sobre os instrumentos musicais. Ele é composto por um CD chamado "ethnic" e outro chamado "fusion", e é justamente para o conteúdo sonoro do produto que pretendo brevemente aqui apontar. No primeiro CD têm-se gravações, feitas em campo, de trechos de performances musicais dos próprios mehináku. No CD "fusion", por outro lado, com a proposta de "fundir as culturas" de índios e brancos, performances de músicos profissionais "ocidentais" são acrescentadas a posteriori, em estúdio, sobre trechos das gravações de campo das performances mehináku. Sugiro que há, ali mesmo no "som da música" do disco fusion, elementos interessantes para se pensar no que possa ser eventualmente entendido por "comunhão cultural" sob a perspectiva de setores de nossa própria sociedade: a música "autêntica" mehináku é ali enquadrada num sistema rítmico, melódico e harmônico que só consegue "tocar junto" impondo-lhe a sua própria moldura, o que acaba evidenciando uma ferida - estética e também política - que é escancarada pela pura e simples sobreposição de sistemas musicais diferentes. A análise musical detalhada quiçá poderá refinar a constatação inicial de que este "enquadramento" da música mehináku pelas gravações de músicos ocidentais que lhe são sobrepostas se dá fundamentalmente pela imposição de padrões rítmicos e tonais estranhos ao código musical mehináku, num efeito de deformação do sistema musical indígena, que passa para segundo plano no produto sonoro final. A "fusão de horizontes" ali pretendida parece resultar antes em sobreposição e enquadramento, construção da ficção de um diálogo surdo e fricativo, onde as mensagens não se ajustam. Pode-se eventualmente argumentar em favor da motivação e do resultado artístico da empreitada - que conta com o trabalho em estúdio de músicos excelentes, além dos magníficos músicos indígenas - mas, para além de qualquer intencionalidade, segundo creio, ela aponta para um certo ruído de fundo, uma certa falta de sintonia, eventualmente despercebida, que tem caracterizado aspectos das relações (estéticas também) entre índios e esta comunidade imaginada que chamamos de Brasil. 
Pensando uma vez mais, e finalmente, no caso específico da demanda dos músicos guarani em direção ao mercado, vemos que, apesar dos ruídos, as cidades do juruá - hoje incomodamente incrustadas no território guarani, segmentando-lhe - parecem estar sistematicamente sendo incluídas, como alvos de mensagens musicais específicas, na rede de comunicações inter-aldeias da qual fala Montardo (1998). Quem sabe uma rede análoga àquela pela qual "antigamente", segundo contam os guarani, quando alguém tocava o ãguá-pú (tambor) numa aldeia, o outro, de longe, já "entendia a mensagem" ${ }^{21}$. Estas mensagens, que agora chegam em forma de CDs e shows, chamam o juruá para conversar, desafiando a falta de sintonia de seus receptores com a insistência sutil de um córrego que flui por entre rochas imensas sem que a pedra lhe consiga impor sua dureza. 


\section{NOTAS}

1 Este texto é baseado na comunicação intitulada "Música como Mercadoria e o Pesquisador como Mediador", que apresentei na 36 ${ }^{a}$ Conferência Mundial do International Council for Traditional Music (ICTM), Rio de Janeiro, 4 a 11 de julho de 2001 . Agradeço as sugestões de meus colegas do MUSA - Núcleo de Estudos "Arte, Cultura e Sociedade na América Latina e Caribe" do PPGAS/ UFSC, especialmente aquelas do professor Rafael José de Menezes Bastos, coordenador do núcleo. Se certamente várias destas sugestões estão incorporadas aqui sem que eu possa sequer mapeá-las, lamento não poder ter incluído, por enquanto, tantas outras. As idéias aqui expressas são, contudo, de minha inteira responsabilidade. Agradeço ao CNPq pela bolsa de mestrado em Antropologia Social (processo $\left.n^{\circ} 131447 / 02-5\right)$, que me permitiu rever este texto concomitantemente ao desenvolvimento de nova pesquisa, em outras paragens (Coelho 2003). Obrigado também aos guarani da aldeia Mbiguaçu, especialmente Seo Alcindo, Dona Rosa, Geraldo, Vanderley, Hyral, Milton e tantos outros, pela generosidade impagável. Finalmente, agradeço à comissão editorial da revista Campos pelas sugestões oriundas de cuidadosa revisão da versão original deste texto.

2 A este respeito, veja Menezes Bastos (2000), Vidal (1991) e Turner (1993).

3 Para notícias sobre o lançamento deste CD, veja também Ricardo (2000:807).

4 Para um panorama relativamente atual da produção acadêmica em antropologia das músicas de povos indígenas das terras baixas da América do Sul, veja, entre outros, Beaudet (1993). Menezes Bastos (1996a e 1999), Menezes Bastos \& Piedade (1999) e Vidal (1991). O trabalho de Tommasino e Resende (2000) sobre o ritual kaingang do Kikikoi é um belíssimo exemplo recente de produção acadêmica de um registro audio-fotográfico.

5 Dallanhol (2002), por exemplo, apresenta uma etnografia bastante atualizada feita junto aos Mbya-Guarani da aldeia de Morro dos Cavalos - SC, onde as atividades do grupo musical Kuaray Oua na região da grande Florianópolis constituem foco de especial atenção.

6 Conforme Ricardo (2000:11)

7 O filme "A Missão" (Joffé 1986) tem como cenário o encontro entre os Estados português e espanhol, os jesuítas e os guarani na região que hoje é compreendida entre as fronteiras do Paraguai, Argentina e Brasil. Nesta obra cinematográfica é ilustrada com propriedade, do ponto de vista histórico, a habilidade musical e o interesse destes últimos pelas músicas exóticas (neste caso, a música trazida pelos jesuítas), recorrentemente mencionados nos escritos da época: os guarani aldeados nas missões revelavamse exímios construtores de instrumentos e executantes da melhor música barroca.

8 Veja Setti (1992 e 1994/95) para considerações sobre o sistema musical Mbyá-Guarani. Conforme também esta autora (1992) para exemplos de inserção de grupos musicais guarani do litoral paulista no mercado do disco.

9 Para dados etnográficos sobre a aldeia Mbiguaçu e suas relações com as aldeias vizinhas, veja também Coutinho (1999).

10 A partir de solicitação dos coordenadores do coral, busquei doações de tecido e mão-de-obra para a confecção de uniformes para as apresentações. A confecção destes foi feita a partir de desenhos, feitos pelos índios, de como os uniformes deveriam ser.

11 Termo utilizado pelos guarani para se referir de um modo geral ao "branco".

12 Em Mbiguaçu há pessoas que freqüentam a aldeia prestando serviços de assistência, seja profissionalmente (como funcionários da FUNASA), seja voluntariamente, algo que parece ser comum nas aldeias guarani da região da grande Florianópolis. Pelo que pude saber em Mbiguaçu, numa rápida visita à aldeia, foi junto a algumas dessas pessoas que encontraram-se canais para a obtenção do dinheiro necessário à gravação e confecção do $C D$, que estaria então em vias de se concretizar. Infelizmente, no momento não possuo mais detalhes sobre o caso.

13 Tal tipo de apropriação é reconhecida por Sahlins, essencialmente em sua dimensão política, como um movimento de ordem mais geral: "Nas últimas duas décadas, vários povos do planeta têm contraposto conscientemente sua 'cultura' às forças do imperialismo ocidental que os vêm afligindo há tanto tempo. A cultura aparece aqui como a antítese de um projeto colonialista de estabilização, uma vez que os povos a utilizam não apenas para marcar sua identidade, como para retomar o controle do próprio destino" (Sahlins 
1997:46) Neste texto, o autor volta à Alemanha do séc. XVIII para encontrar, num forjamento inicial do conceito de cultura por Herder, não aquele pacto pecaminoso com o colonialismo, alvo de tantas elucubrações e críticas pós-modernas, mas justamente uma intenção que, na origem, é anticolonialista, opondo-se neste caso específico à idéia iluminista de uma "razão universal".

14 A divisão dos guarani em três subgrupos - nhandéva, mbÿá e kaiová - é tema recorrente na literatura etnológica. A este respeito conforme, entre outros, o próprio Schaden (1962), Nimuendaju (1987) e Montardo (2002).

15 Note-se nas letras a persistência de temas mítico-cosmológicos centrais para os guarani, como a busca da Terra sem Males. A comparação musicológica, sem a qual o estudo das letras é sempre demasiadamente parcial e incompleto, fica na dependência do acesso a gravações deste repertório que possivelmente tenham sido feitas por Schaden, algo que seria extremamente interessante para um estudo da prática musical guarani que abrangeria uma profundidade temporal de meio século.

16 Veja, por exemplo, os trabalhos de Townsley (1993) sobre o dinamismo do xamanismo Yaminahua (Peru) em situações intensas de contato com o "homem branco", Brown e Fernández (1991) para a complexidade da associação entre os Asháninkas e movimentos revolucionários de esquerda no Peru durante a década de 60, Menezes Bastos (1995) para uma compreensão dos diversos processos de contato que atuam na conformação da atual ocupação humana do Alto-Xingu, Heckenberger (2000) e Roosevelt (1992) para estudos que apontam - sob uma perspectiva arqueológica - para um quadro de ocupação humana na América do Sul anterior ao século XVI que de forma alguma pode ser entendido como "simples".

17 Veja Litaiff (1996:13-17) para um interessantíssimo relato de como integrantes de um grupo Mbyá-Guarani foram transformados em índios para atuarem nas filmagens de um programa de televisão.

18 Pude fazer uma exploração extremamente inicial de formas de afinação do mbaraká nas aulas de teoria musical que tive com os músicos guarani em Mbiguaçu (Coelho 1999). Setti (1994/95) explora o tema de forma mais aprofundada. O que chama a atenção, de qualquer forma, é o extremo cuidado que os músicos guarani dedicam à afinação de seus instrumentos, que toma longos minutos antes do início das performances.

19 Entendo o "centro tonal" ou "tônica" de uma melodia, com base em Menezes Bastos (1989), como o grau de mais alta hierarquia da escala (repertório de sons) musical - entendida como sistema axionômico culturalmente definido e elaborado. Ele age como uma espécie de centro gravitacional, e o critério fundamental para sua estipulação é a localização, dentro do contexto tonal de determinada melodia, de pontos de convergência e estabilização do movimento melódico, conforme Coelho (2003:84-85) e também Montardo (2002:73).

20 Para uma etnografia deste povo veja Gregor (1977).

21 Conforme me relatou um jovem índio da aldeia Mbiguaçu. 


\section{REFERÊNCIAS BIBLIOGRÁFICAS}

ALBERT, Bruce. 1993. “L'Or cannibale et la chute du ciel”. L'Homme 126-128: 349-378.

AROM, Simha. 1991. African Polyphony \& Polyrhythm. Cambridge: Cambridge University Press.

BEAUDET, Jean-Michel. 1993. “L'Ethnomusicologie de l'Amazonie". L'Homme 126-128: 527-533.

BROWN, Michael F. \& Eduardo Fernández. 1991. War of Shadows: The Struggle for Utopia in the Peruvian Amazon. Berkeley: University of California Press.

CHAUÍ, Marilena. 2002. Introdução à História da Filosofia - Vol. 1. São Paulo: Companhia das Letras.

COELHO, Luís Fernando Hering. 1999. "Canções Guarani entre os Nhandéva da Aldeia de Biguaçu-SC". Trabalho de Conclusão de Curso. Florianópolis: UDESC/Departamento de Música.

. 2000. “Tradição e Inovação na Música Guarani - Reflexões a Partir da Aldeia Mbiguaçu”. Manuscrito.

2003. Para Uma Antropologia da Música Arara (Caribe): Um Estudo do Sistema das Músicas Vocais. Dissertação de Mestrado. Florianópolis: UFSC.

COUTINHO, Maria Rosa M. 1999. “Nosso Modo de Ser” - Representações sobre saúde e doença entre os Guarani Nhandéva. Dissertação de Mestrado. São Carlos: UFSCAR.

DALLANHOL, Kátia Maria Bianchini. 2002. Jeroky e Jerojy: por uma antropologia da música entre os Mbyá-Guarani do Morro dos Cavalos. Dissertação de Mestrado. Florianópolis: UFSC.

DEHOUX, Vincent. 1992. “Centrafrique - Musique Gbáyá/Chants à penser”. Texto encartado no CD de mesmo nome. Paris: Ocora/Radio France - C 580008.

GREGOR, Thomas. 1977. Mehinaku: The Drama of Daily Life in a Brazilian Indian Village. Chicago: The University of Chicago Press.

HECKENBERGER, Michael. 2000. “Estrutura, História e Transformação: a Cultura Xinguana na 'Longue Durée'”. In Bruna Franchetto e Michael Heckenberger (orgs). Os Povos do Alto Xingu: História e Cultura. Rio de Janeiro: Editora UFRJ.

LENOBLE, R. 1990. História da Idéia de Natureza. Lisboa: Edições 70.

LÉVI-STRAUSS, Claude. 1993. História de Lince. São Paulo: Companhia das Letras.

LITAIFF, Aldo. 1996. As Divinas Palavras - Identidade Étnica dos Guarani-Mbyá. Florianópolis: Editora da UFSC.

MENEZES BASTOS, Rafael José de. 1989. A Festa da Jaguatirica: Uma Partitura Crítico-Interpretativa. Tese de Doutorado. São Paulo: USP.

. 1995. “Indagação Sobre os Kamayurá, o Alto-Xingu e Outros Nomes e Coisas: Uma Etnologia da Sociedade Xinguana". Anuário Antropológico/94: 227-269.

1996. “Musicalidade e Ambientalismo na Redescoberta da Eldorado e do Caraíba: uma Antropologia do Encontro Raoni-Sting". Revista de Antropologia 39(1): 145-189.

. 1996a. "Música nas Terras Baixas da América do Sul: ensaio a partir da escuta de um disco de música Xikrín". Anuário Antropológico/95: 251-263.

1999. Music in Lowland South America: State of the Art. Hiroshima: Paper presented at the $35^{\text {th }}$ World Conference

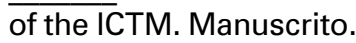


2000. Authenticity and Divertissement: Phonography, American Ethnomusicology and the Market of Ethnic Music in the United States of America. Berlim: Paper presented to the international conference on the occasion of the 100 anniversary of the Berliner Phonogramm-Archive. Manuscrito.

MENEZES BASTOS, Rafael José de \& Acácio Tadeu de C. Piedade. 1999. “Sopros da Amazônia: Ensaio-Resenha Sobre as Músicas das Sociedades Tupi-Guarani". Mana 5(2): 125-143.

MONTARDO, Deise Lucy Oliveira. 1998. "Etnografia Musical na Aldeia Guarani-Nhandeva Pirajui - Paranhos/MS". Comunicação apresentada na XXI Reunião Brasileira de Antropologia. Vitória, 05-09/04/1998. Manuscrito. . 1999. “Ñande Reko Arandu - Memória Viva Guarani”. Resenha de CD. Horizontes Antropológicos 11: $203-205$. 2002. Através do Mbaraka: Música e Xamanismo Guarani. Tese de Doutorado. São Paulo: USP.

NIMUENADAJU, Curt. 1987 [1914]. As Lendas da Criação e Destruição do Mundo. São Paulo: HUCITEC / EDUSP.

PIEDADE, Acácio Tadeu de C. 1997. “Música Ye'pâ-masa: Por uma Antropologia da Música no Alto Rio-Negro”. Dissertação de Mestrado. Florianópolis: UFSC.

RICARDO, Carlos Alberto (ed). 2000. Povos Indígenas no Brasil 1996-2000. São Paulo: Instituto Socioambiental.

ROOSEVELT, Anna Curtenius. 1992. “Arqueologia Amazônica”. In: Manuela Carneiro da Cunha (org). História dos Índios no Brasil. São Paulo: Companhia das Letras.

SAHLINS, Marshall. 1997. “O ‘Pessimismo Sentimental’ e a Experiência Etnográfica: por que a cultura não é um ‘objeto’ em vias de extinção". (Partes I e II). Mana 3(1):41-73 e 3(2):103-150.

SCHADEN, Egon. 1962. Aspectos Fundamentais da Cultura Guarani. São Paulo: Difusão Européia do Livro.

SEEGER, Anthony. 1987. Why Suya Sing. Cambridge: Cambridge University Press.

SETTI, Kilza. 1992. “Questões relativas à autoctonia nas culturas musicais indígenas da atualidade, consideradas no exemplo dos Mbyá-guarani". Revista Brasileira de Música 20: 33-41.

1994/95. "Os Índios Guarani-Mbyá do Brasil: Notas sobre sua história, cultura e sistema musical”. Musices Aptatio. Lieber Annuarius: 73-145.

TOMMASINO, Kimiye \& Jorgisnei Ferreira de Rezende. 2000. Kikikoi: Ritual dos Kaingang na Área Indígena Xapecó/SC. Londrina: Midiograf/NMC/UEL/CIMI (acompanha CD).

TOWNSLEY, Graham Elliot. 1993. "Song Paths: The Ways and Means of Yaminahua Shamanic Knowledge". L'Homme 126128: 449-468.

TURNER, Terence. 1993. “Imagens Desafiantes: a Apropriação Kayapó do Vídeo”. Revista de Antropologia 36: 81-121.

VAN VELTHEM, Lúcia Hussak. 1995. O Belo é a Fera: A estética da produção e da predação entre os Wayana. Tese de Doutorado. São Paulo: USP.

VIDAL, Lux B. 1991. “As Pesquisas mais freqüentes em etnologia e história indígena na Amazônia: uma abordagem musical." Revista de Antropologia: 183-196.

VIVEIROS DE CASTRO, Eduardo. 1986. Araweté: Os Deuses Canibais. Rio de Janeiro: Zahar/ANPOCS. . 1992. “O Mármore e a Murta: Sobre a Inconstância da Alma Selvagem." Revista de Antropologia 35: $21-74$. 2000. “Os Termos da Outra História". Povos Indígenas no Brasil 1996/2000: 49-54. 


\section{REFERÊNCIAS FONO E VIDEOGRÁFICAS}

FONSECA DE OLIVEIRA, Antônio Maurício (dir). 1998. Nande Reko Arandu - Memória Viva Guarani, 1CD, MGV-2001. JOFFÉ, Roland (dir). 1986. A Missão (The Mission). Columbia Pictures.

PINAGÉ, Paulo (prod). 2001. Mehinaku - Message from Amazon, 2 CDs, MCD 097.

TOMBINI, Anderson (prod). 2000. Mboraí Marae-ÿ - Cantos Sagrados, 1 CD, CDG199W. 


\section{Música Indígena no Mercado: sobre demandas, mensagens e ruídos no (des)encontro intermusical} RES U M 0

Focalizo aqui brevemente a relação entre músicos indígenas - com ênfase no universo guarani - e o mercado da música, apontando para elementos específicos das demandas aí envolvidas. Se o lado indígena mostra sistemas estético-musicais abertos e flexíveis, ao lado da busca por caminhos de articulação política junto à sociedade envolvente, do lado do mercado a demanda se caracteriza em grande parte pela busca de um "índio" estereotipado ao qual seria negada a possibilidade de "mudar". Na parte final, alguns dos pontos levantados são considerados no exame de duas produções fonográficas recentes envolvendo músicas indígenas - guarani num caso e mehináku no outro.

PALAVRAS-CHAVE: Antropologia da Música, índios Guarani, contato intercultural

Indigenous music in the market: about demands, messages and noises in inter-musical (dis)encounters A B S TR A C T

The article focuses the relation between indian musicians - with emphasis in the guarani universe - and the music market, pointing to specific elements of the demands involved. If the indian side shows open and flexible aesthetic-musical systems, coupled with the search for politic articulations with the more encompassing society, the markets' demand characterizes itself to a large extent in the search of a stereotyped "indian" to whom it would be denied the possibility of "change". In the final part, some of the points raised are considered in the examination of two recent phonographic productions involving traditional musicians - Guarani in one case and Mehináku on the other.

KEY WORDS: Anthropology of Music, Guarani Indians, Intercultural Contact 